Article

\title{
Analysis of the Flow Performance of the Complex Cross-Section Module to Reduce the Sedimentation in a Combined Sewer Pipe
}

\author{
Hyon Wook Ji ${ }^{1}$, Sung Soo Yoo ${ }^{1}$, Dan Daehyun Koo ${ }^{2}$ and Jeong-Hee Kang ${ }^{1, *(1)}$ \\ 1 Department of Land, Water, and Environment Research, Korea Institute of Civil Engineering and Building \\ Technology, 283, Goyang-daero, Ilsanseo-gu, Goyang-si, Gyeonggi-do 10223, Korea; \\ jihyonwook@kict.re.kr (H.W.J.); yoosungsoo@kict.re.kr (S.S.Y.) \\ 2 Department of Engineering Technology, Indiana University-Purdue University Indianapolis (IUPUI), \\ 799 W. Michigan St. ET 314J, Indianapolis, IN 46202, USA; dankoo@iupui.edu \\ * Correspondence: kangjeonghee@kict.re.kr; Tel.: +82-10-7193-0798
}

Received: 5 November 2020; Accepted: 19 November 2020; Published: 23 November 2020

check for updates

\begin{abstract}
The difference in the amount of stormwater and sewage in a combined sewer system is significantly large in areas where heavy rainfall is concentrated. This leads to a low water level and slow flow velocity inside the pipes, which causes sedimentation and odor on non-rainy days. A complex cross-section module increases the flow velocity by creating a small waterway inside the pipe for sewage to flow on non-rainy days. While considering Manning's equation, we applied the principle where the flow velocity is proportional to two-thirds of the power of the hydraulic radius. The flow velocity of a circular pipe with a diameter of $450 \mathrm{~mm}$ and the corresponding complex cross-section module was analyzed by applying Manning's equation and numerical modeling to show the effects of the complex cross-section module. The tractive force was compared based on a lab-scale experiment. When all conditions were identical except for the cross-sectional shape, the average flow velocity of the complex cross-section module was $14 \%$ higher while the size of the transported sand grains was up to $0.5 \mathrm{~mm}$ larger. This increase in flow velocity can be even higher if the roughness coefficient of aging pipes can be decreased.
\end{abstract}

Keywords: combined sewer system; tractive force; CFD modeling; sedimentation; odor

\section{Introduction}

A sewer system discharges, processes, and utilizes sewage and human waste as well as processing and using sludge. As a result, sewer systems prevent flooding, they improve the living environment, and they can control the water quality [1-3]. A sewer is buried underground for carrying the sewage away from the living zone in which the system is classified into a separate sewer or a combined sewer system depending on the discharge method. A sewer pipe and a stormwater pipe are distinguished in a separate sewer system for allowing only sewage to be transported to treatment plants. This improves the operation efficiency of treatment plants, and it helps with controlling the water quality since sewage is not discharged into rivers during rainfall. However, the drawbacks of this system include: the highly polluted initial stormwater is directly discharged into rivers, the burial depth of the sewer pipe is deep, and the construction of two types of pipelines increases the complexity. On the other hand, both sewage and stormwater are transported together in one pipe in a combined sewer system. This separation method enables a certain amount of initial stormwater to be collected, the pipelines can be cleaned by stormwater, and the complexity of a pipe network can be reduced. The separate and combined sewer systems are used accordingly depending on the situation since the combined sewer system causes river 
pollution due to combined sewer overflow (CSO) and a decreased processing efficiency at treatment plants due to a large amount of stormwater being collected [4]. The design manual for a sewer system in the United States and Europe specifies different standards for the velocity for a combined sewer system and a separate sewer system; thus, giving an option in the design process [5].

Sewage odor is a problem that has yet to be solved in separate and combined sewer systems, which degrades the quality of life for all individuals [6-8]. However, there is also a problem unique to the combined sewer system. That is, the sedimentation and odor are caused by the difference in the flow rate on non-rainy days and rainy days [9].

In South Korea, the standard flow velocity of a combined sewer system is between $0.8 \mathrm{~m} / \mathrm{s}$ and $3 \mathrm{~m} / \mathrm{s}$ for the designed rainfall. The annual average precipitation is $1277 \mathrm{~mm}$, where $50-60 \%$ of rainfall occurs in the summer. Hence, the amount of sewage in most places around the country is less than $1 \%$ of the amount of stormwater. The flow rate condition of the design stormwater flow is satisfied due to a large difference in the amount of stormwater and sewage. However, when the flow rate and flow velocity decrease on non-rainy days, the remaining substances introduced in the event of heavy rainfalls and particulates contained in sewage are deposited. This reduces the discharge capacity, it causes an odor [8], and it worsens the concentration of CSO $[10,11]$. The problems mentioned above are a common concern for regions where heavy rainfall occurs at a specific time.

In the mid-1800s and early 1900s, sewer pipes of various shapes were constructed in Europe using bricks [12]. The lower sections of these sewers, where sewage flows, is smaller than the top section, which is designed for stormwater flow and maintenance. With advances in construction techniques and the widespread adoption of sewage systems, which improved public health worldwide [13], construction speed became an important factor. Hence, circular and square sewer pipes were mass produced in factories and transported on vehicles. However, in combined sewer systems, problems arise over time because of the inefficiency of pipes with simple cross-sections in handling different flow rates on non-rainy and rainy days.

Manufacturing sewer pipes with different sizes and shapes besides a circular or square shape at mass production factories is economically and technically challenging. An egg-shaped sewer pipe can appropriately handle the difference in the flow rate on non-rainy days by combining the sewer pipe and stormwater pipe; however, it is rarely used in practice [14]. Therefore, a complex cross-section module has been developed, which can be inserted into a regular circular sewer pipe to be assembled, as shown in Figure 1. The complex cross-section module can generate a high flow velocity, even at low flow rates on non-rainy days by making a sewer pipe at the bottom of a combined sewer system. A faster flow velocity than the existing pipes can be exhibited at the same slope by increasing the hydraulic radius. This module is placed on only a part of the bottom surface; thus, the entire pipe can be used on rainy days to handle the design rainfall sufficiently. The module should be heavier than buoyancy, solid to maintain shape, and corrosion resistant; this study used polyvinyl chloride (PVC). The module can be inserted from manholes without the need for excavation, which does not cause traffic interruptions during construction. After pre-cleaning and by-pass pumping complex cross-section modules should be inserted, after the insertion the inverts of the manholes need to be constructed. In this study, the hydraulic performance-particularly, flow velocity and tractive force-of a complex cross-section module developed for circular pipes was verified using computational fluid dynamics (CFD) modeling, Manning's equation, and a lab-scale experiment.

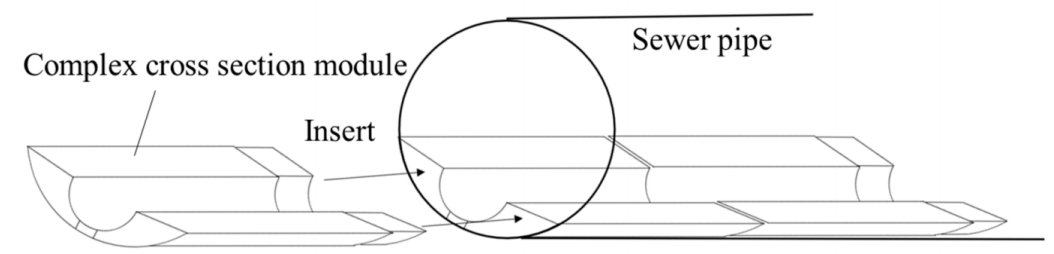

Figure 1. Schematics of the installation of complex cross-section modules in a sewer pipe. 


\section{Methodology}

\subsection{Complex Cross-Section Module Definition}

The complex cross-section module is a device for creating a waterway for sewage on the bottom of a combined sewer system on non-rainy days. The complex cross-section module consists of a waterway, a side slope, and a bottom as shown in Figure 2. Since the complex cross-section module is installed in existing sewer pipes, it must be manufactured to perfectly fit the bottom of the sewer pipe. The bottom of the module comes in contact with the combined sewer system; thus, it has the same diameter as that of the combined sewer pipe. The side slope forms slopes to prevent sewage or particulates from settling, and it is sloped at $10 \%$ so it is extended from the invert of the manholes. The waterway through which the sewage flows must be designed in a form to have the highest flow velocity, flow rate, and size to accommodate the amount of sewage being generated by people within the applicable range. Figure 2 illustrates the semicircular waterway, which has a diameter of $150 \mathrm{~mm}$. Its design was based on a D450 mm sewer pipe due to the following reasons.

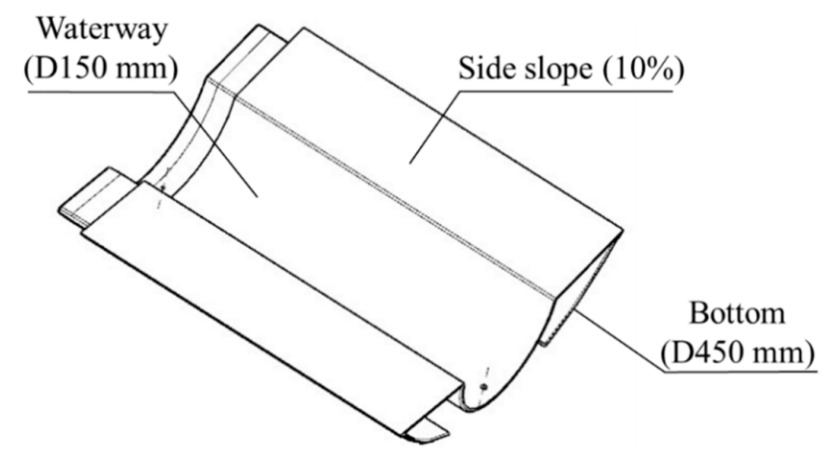

Figure 2. A complex cross-section module for the D450 mm sewer pipe.

Manning's equation, as shown in Equation (1) below, is commonly used for designing a sewer system [15]. The flow velocity is proportional to two-thirds of the power of the hydraulic radius when the material and the slope of the pipe are constant. Therefore, the shape with a greater hydraulic radius must be identified.

$$
\mathrm{v}=\frac{1}{n} R_{h}^{2 / 3} S^{1 / 2}
$$

where, $v$ is the flow velocity $(\mathrm{m} / \mathrm{s}), n$ is Manning's roughness coefficient, $R_{h}$ is the hydraulic radius (m), and $S$ is the slope.

In Table 1, the flow velocity and flow rate have been calculated for three shapes: a cup, a semicircle, and a triangle. These three shapes all have the same cross-sectional area (1808 $\left.\mathrm{mm}^{2}\right)$, Manning's roughness coefficient (0.01), and slope (0.01). However, the triangle has the highest discharge capacity, with a flow rate of $1.23 \mathrm{~L} / \mathrm{s}$, a flow velocity of $0.678 \mathrm{~m} / \mathrm{s}$, and a central angle of $63.4^{\circ}$. As the waterway protrudes from the structure, it experiences bending moment. The longer and thinner this protrusion, the more vulnerable it is to this bending moment; hence, the waterway should not be too deep. In addition, narrow waterways must be avoided to facilitate cleaning and form removal. In other words, the waterway must be easy to clean in order to ensure adequate flow on non-rainy days. Considering these requirements, the semicircle is the efficient shape, especially given its high discharge rate with a flow rate of $1.2 \mathrm{~L} / \mathrm{s}$ and a flow velocity of $0.661 \mathrm{~m} / \mathrm{s}$. 
Table 1. Size and discharge capacity of the cross-section shapes under a common condition.

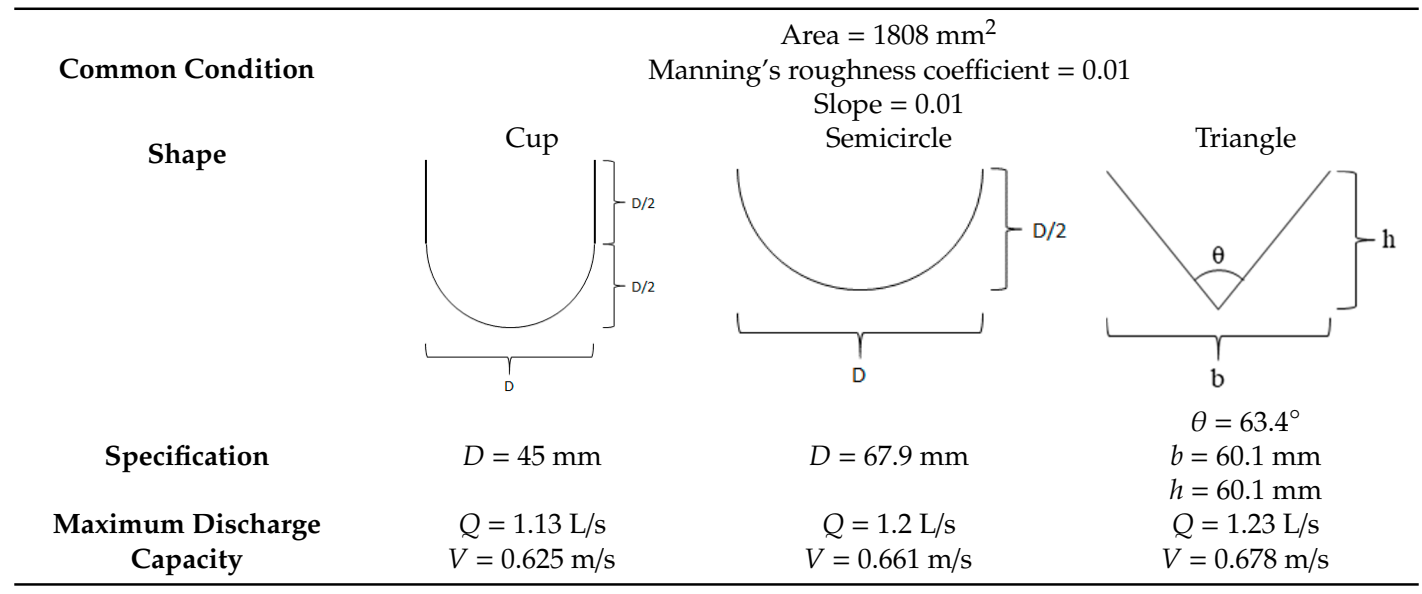

Since the diameter, which determines the size of the semicircle waterway, must accommodate the amount of sewage that is being generated, the ratio (Equation (2)) of the cross-sectional area of the sewage flow to the entire cross-sectional area was examined from 56,259 combined sewer pipes with a diameter between 450 and $1300 \mathrm{~mm}$ in 24 small watersheds in Seoul.

$$
\lambda=\alpha / A
$$

where $\alpha$ is the cross-sectional area of the sewage flow, $A$ is the entire cross-sectional area of a sewer pipe, and $\lambda$ is the ratio between the two areas. Figure 3 presents the distribution of $\lambda$ according to the pipe diameter. The median value of $\lambda$ is located around 0.005 , while Q3, which comprises $75 \%$ of the data, is around 0.01 . The suspected outliers above Q3 either have counter-gradient variation or are affected by infiltrating water. They are observed only in sewer pipes with a diameter of $600 \mathrm{~mm}$ or below. All other suspected outliers are mostly below Q1. This is partly because the sewer pipes in Korea are designed to be large in comparison to the sewage amount for a smooth drainage, in which localized heavy rainfall frequently occurs. Similar tendencies are observed in pipes of all diameters.

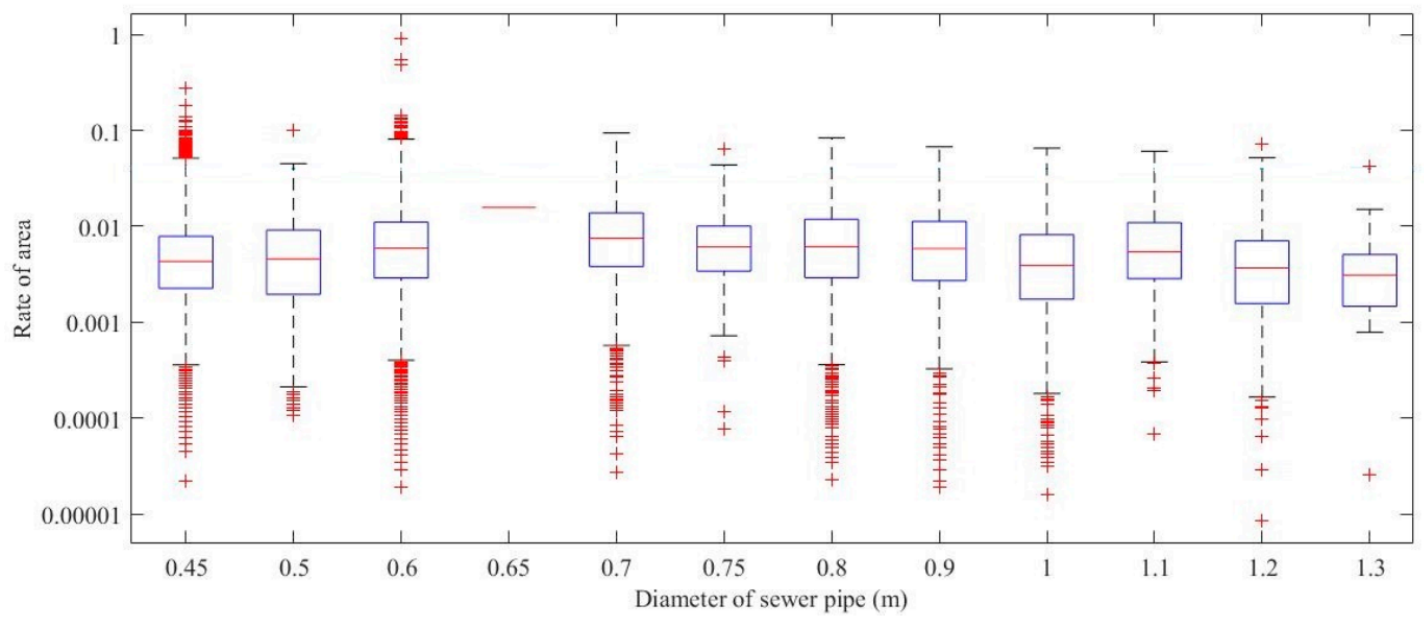

Figure 3. Box plot for the rate of area between the pipe and sewage flow by the diameter. 
When descriptive statistics for all $\lambda$ values are calculated regardless of the pipe diameter, the mean $\lambda$ is 0.0074 and the standard deviation is 0.0112 . When $\lambda$ is fitted to the normal distribution using these values, it has the distribution of $\mathrm{N}(0.0074,0.0112)$. According to the probability density function of a normal distribution, the average $\lambda$ can cover $50 \%$ of the entire distribution, while 0.041 , which is $3 \sigma$ greater than the average $\lambda$, can cover $99.9 \%$ of the entire distribution [16]. The $\lambda$ value is adjusted to the common value of 0.04 based on these results. In addition, $\lambda$ can be applied to these pipes with a diameter between 450 and $1300 \mathrm{~mm}$. Based on this analysis, the diameter of an auxiliary pipe is $127 \mathrm{~mm}$ in a sewer pipe with a diameter of $450 \mathrm{~mm}$. However, since pipes are currently manufactured with diameters of only 100, 125, 150, and $200 \mathrm{~mm}$, the pipe was required to have a diameter of $150 \mathrm{~mm}$ based on the manufacturing standard.

\subsection{CFD Model}

Average velocity and water level were calculated for the $450 \mathrm{~mm}$ circular pipe and the $150 \mathrm{~mm}$ complex cross-section module by Manning's equation. Manning's equation is a function of the roughness coefficient, hydraulic radius, and slope as demonstrated in Equation (1). The hydraulic radius among these variables is affected by the waterway shape. The module can be analyzed as a circular pipe having a diameter of $150 \mathrm{~mm}$ because sewage only flows through a small waterway on non-rainy days.

Although Manning's equation is applied to sewer design it is an empirical equation. The result by Manning's equation was checked by a numerical model solving Navier-Stokes equations describing the motion of viscous fluid substances. Only the shape of the cross-sections were varied, while keeping all of the conditions, including the slope and roughness coefficient, identical in order to examine the difference in the performance based on the shape like the comparison method using Manning's equation.

This study used ANSYS CFX 19.1 software (ANSYS, Inc., Canonsburg, PA, USA), which is capable of analyzing fluids in various shapes and used in sewer pipes [14], as a numerical model. This numerical model solves the 3D Reynolds-averaged Navier-Stokes equations [17]. The volume of fraction (VOF) and homogeneous turbulence models were applied among the different multiphase approaches in

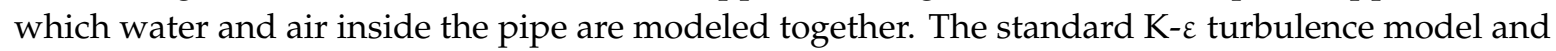
hydrostatic pressure buoyancy model were applied. Boundary conditions of two domain were set from discharge condition. The bulk mass flow rate for the inlet condition and opening pressure for the outlet condition were applied so they can be analyzed as steady state. The no slip wall condition and equivalent roughness of $0.244 \mathrm{~mm}$ were applied to the pipe wall in order to create a similar effect as the Manning's roughness coefficient of 0.01 by Strickler's equation $\left(k_{s}=(n \times 25)^{6}\right)$ [14]. The pipe is designed with an unstructured non-uniform mesh by $1.8 \times 10^{6}$ elements by using a $20 \mathrm{~m}$ length. The modeling conditions and mesh quality are summarized in Table 2 . The slope was adjusted to $0.005,0.01$, and 0.015 , while fixing the flow rate at $0.001668 \mathrm{~m}^{3} / \mathrm{s}$. In the same conditions as specified above, the discharge capacity of the D450 circular pipe and a sewer pipe in which D450/D150 (complex cross-section module) is installed was compared. 
Table 2. Domain and condition for numerical modeling.

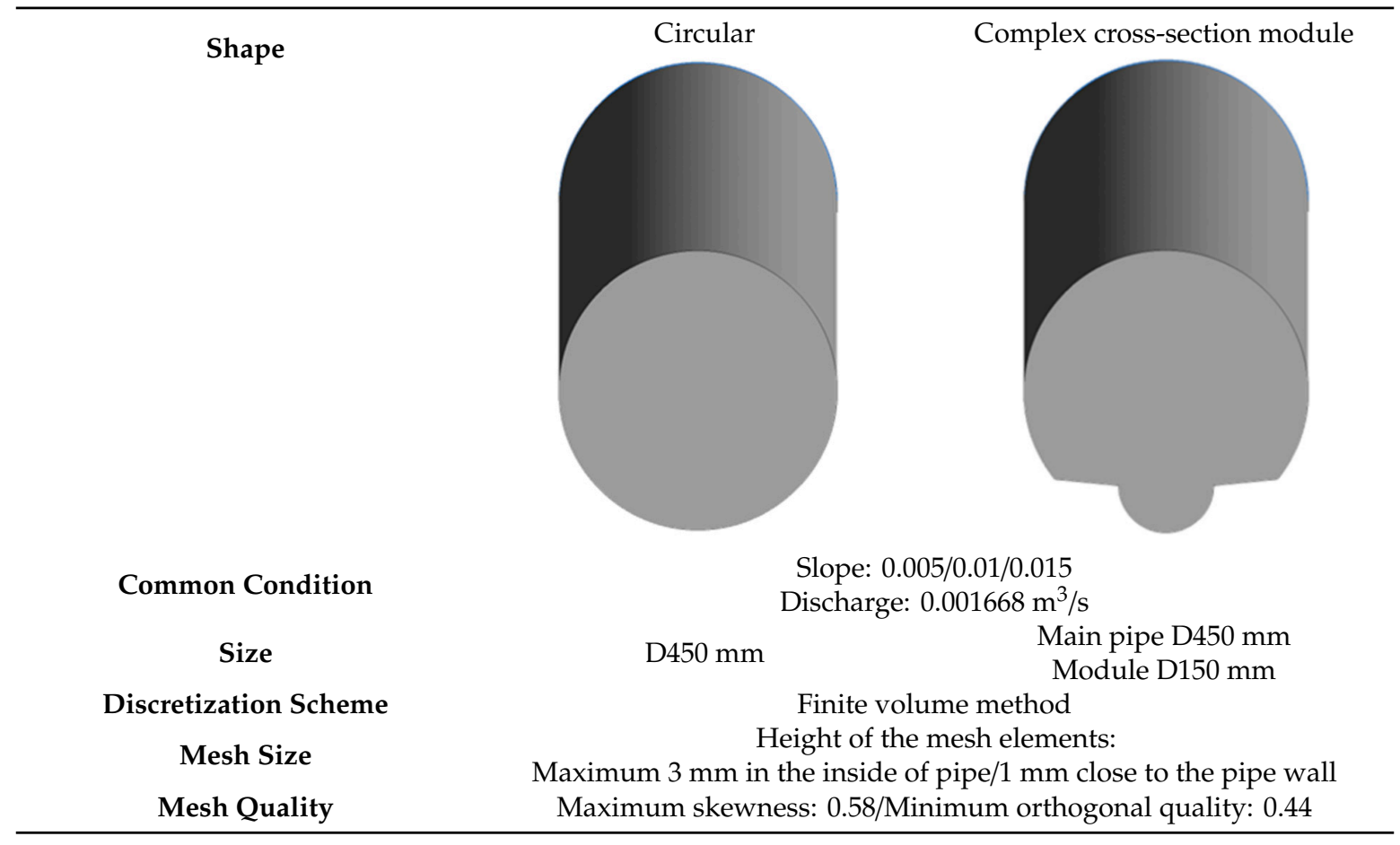

\subsection{Experimental Setup}

The experimental device shown in Figure 4 was designed to compare the discharge capacity and the tractive force of the complex cross-section module. During the lab-scale experiment, all conditions were identical except for the cross-sectional shape to compare the difference in the performance according to the pipe shape. Two waterways with a $20 \mathrm{~m}$ length were arranged in parallel, and the slope control motor set in the front and back of the waterways adjusted the slope at 0.0075 . A PVC pipe having a diameter of $450 \mathrm{~mm}$ was cut in half and then placed on two waterways each, and the complex cross-section module was installed on one of the pipes. A total of 40 complex cross-section modules, which were manufactured with PVC over $0.5 \mathrm{~m}$ as shown in Figure 2, were installed on the waterways. Manning's coefficient for PVC is 0.01 . Water was collected at the outlet chamber and then it was sent to the water upstream through a pump after which the water parted into the circular pipe and the complex cross-section module. A total of three flowmeters were installed in front of the pump and the valve for each of the two waterways for measuring the total flow rate of the pump. The flow rate was measured again before the water falls into the waterways so it can be summed and compared. In addition, the flow velocity and water level were measured at the measurement point that is located $18 \mathrm{~m}$ from the inlet. The flow velocity was measured with a contact-type propeller hydrometer. The water level was measured with a ruler so it can be used in Manning's equation to calculate the flow velocity and flow rate, which compared the values that were measured by the flowmeter and were then averaged. This method can minimize the error in the flowmeter and hydrometer. The slope of the waterway was measured by using an infrared ray distance and a slope meter. 


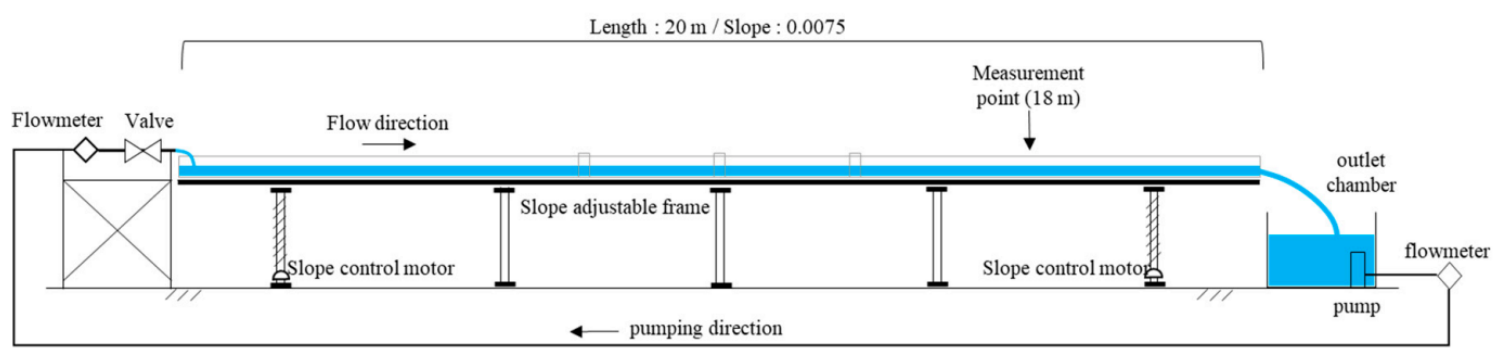

Figure 4. Schematic drawing of the experimental sewer pipelines for particle transportation.

An increase in the flow velocity causes a decrease in the sedimentation amount; however, the correlation between the flow velocity and sedimentation is not directly reflected when designing a sewer system. However, the sedimentation capacity was examined in this study since sedimentation in the sewer system is an important factor for determining the functionality after the construction of a sewer system. According to a study by Haestad et al. [18], tractive force is generated when the shear stress of water exceeds the critical shear stress of the particles (Equation (3)).

$$
\tau_{c}=0.867 d^{0.277}
$$

where, $\tau_{c}$ is the critical shear stress $\left(\mathrm{N} / \mathrm{m}^{2}\right)$ of the sand grains, and $d$ is the diameter $(\mathrm{mm})$ of the particles with a specific gravity of 2.7. As demonstrated in Equation (3), the critical shear stress of the sand grains is proportional to the particle size. This implies that the waterway has a greater tractive force as the size of the particles being transported increases.

By comparing the tractive force that is based on the size of the particles which can be transported through the circular pipe and the complex cross-sectional module, sand with a particle size distribution of up to $4.75 \mathrm{~mm}$ diameter (Figure 5) was dropped at the inlet of the waterways. Then, the water falling from the outlet chamber passes through a No. 50 sieve for $20 \mathrm{~min}$ to collect the sand flowing out of the waterways. The intensity of the tractive force can be compared by examining the size of the sand grains that are collected from each waterway.

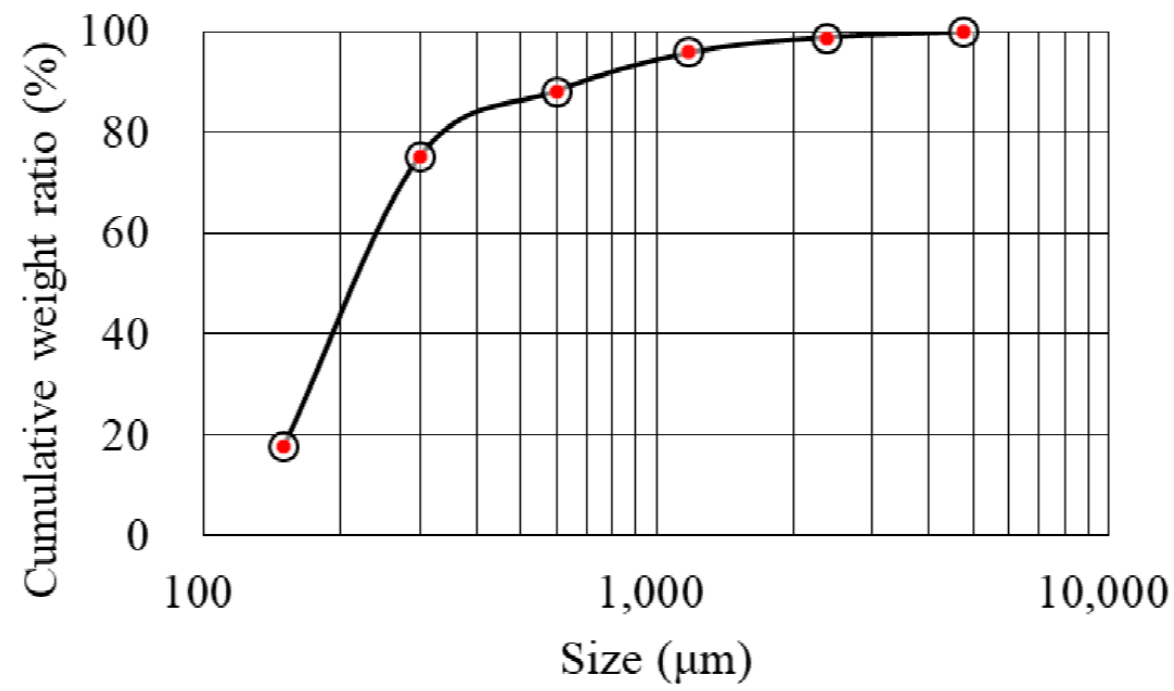

Figure 5. Cumulative distribution of the particle size for the tractive force experiment. 


\section{Results}

\subsection{Velocity Distributions}

As presented in Table 2, the velocity distribution from the CFD modeling when the slope is 0.005 at a flow rate of $0.001668 \mathrm{~m}^{3} / \mathrm{s}$ as illustrated in Figure 6 . At the same flow rate, the complex cross-section module has a higher water level as well as the area corresponding to the flow velocity, which is $0.7 \mathrm{~m} / \mathrm{s}$ or greater. The cross-sectional area of the flow is shallow in the circular pipe, resulting in a larger area being contacted at the pipe surface and a larger effect of the pipe surface on the velocity field. This principle is intuitively explained by a hydraulic radius. A smaller hydraulic radius in the circular pipe signifies that the wetted perimeter is longer in comparison to the cross-sectional area of the flow. Therefore, the velocity field decreases overall as the friction area against air or the pipe wall is relatively larger than the cross-sectional area of the flow.

The average flow velocity of the CFD and Manning's equation are listed in Table 3. As the slope becomes steeper, the flow velocity becomes faster and the water level is reduced. The water level at the same slope is always higher in the complex cross-section module than the circular pipe. The average flow velocity is also higher in the complex cross-section module for both CFD modeling and Manning's equation. As the hydraulic radius increased due to the raised water level, the average flow velocity of Manning's equation increased, and the flow velocity increased at a rate of $13-14 \%$.

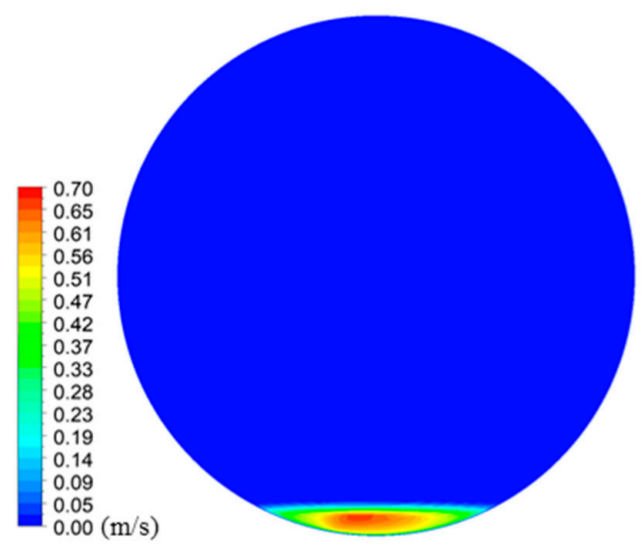

(a) Circular pipe

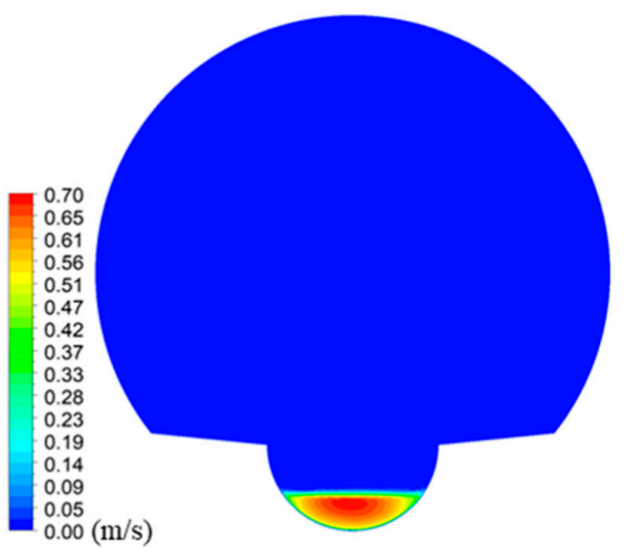

(b) Complex cross-section module

Figure 6. Velocity distribution by numerical modeling of circular pipe (a) and complex cross-section module (b) for $Q: 0.001668 \mathrm{~m}^{3} / \mathrm{s}, S: 0.005$.

Table 3. Average velocity and water level of the circular pipe and the complex cross-section module.

\begin{tabular}{ccccc}
\hline \multirow{2}{*}{ Analysis Method } & \multirow{2}{*}{ Shape } & \multicolumn{3}{c}{ Average Velocity (m/s)/Water Level (mm) } \\
\cline { 3 - 5 } & & Slope 0.005 & Slope 0.01 & Slope 0.015 \\
\hline \multirow{2}{*}{ CFD } & Circle & $0.493 / 24.5$ & $0.638 / 20$ & $0.739 / 19$ \\
Manning's & Complex & $0.569 / 33.5$ & $0.742 / 28$ & $0.868 / 26.5$ \\
equation & Circle & $0.462 / 25.7$ & $0.586 / 21.8$ & $0.677 / 19.9$ \\
& Complex & $0.533 / 35$ & $0.682 / 29.5$ & $0.787 / 26.7$ \\
\hline
\end{tabular}

In general, the maximum flow velocity in open channels is approximately $5-25 \%$ of the water depth [19]; the centerline velocity profile in Figure 7a also exhibits a similar tendency. With respect to the circular pipe, the complex cross-section module has a similar but better flow velocity distribution from the bottom to the depth of the maximum flow velocity. After the maximum flow velocity of the circular pipe has been reached, the complex cross-section module has a greater water depth and the difference in the flow velocity increases even more until the maximum flow velocity is reached. This is demonstrated in Figure $7 \mathrm{~b}$. No difference was found around the bottom, but the difference 
is significant when the water depth is $0.01-0.04 \mathrm{~m}$. This result leads to a significant difference in the average flow velocity.

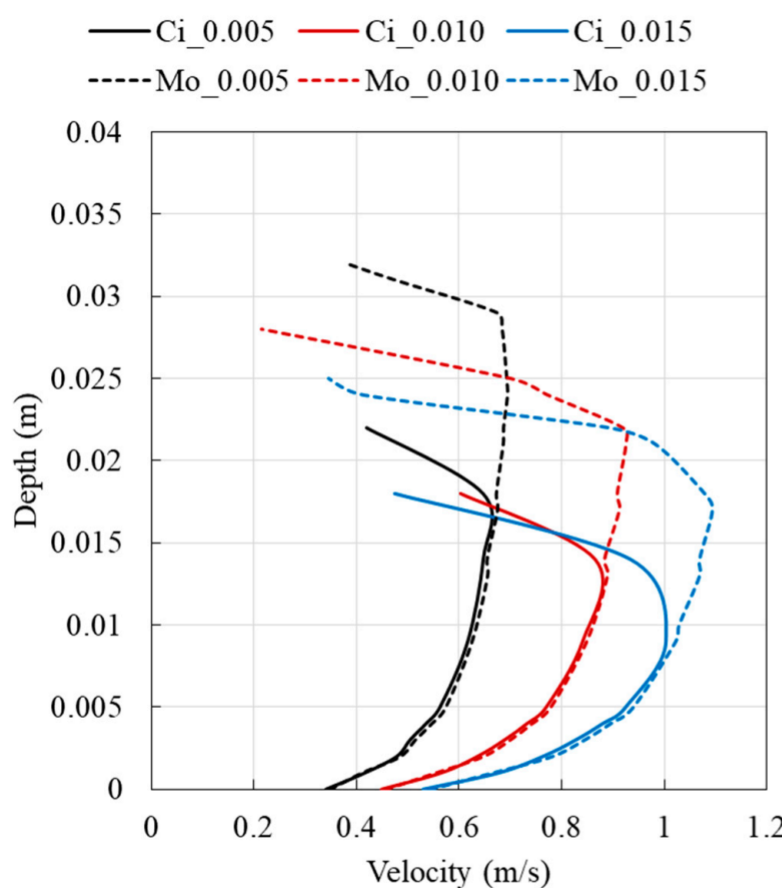

(a) Centerline velocity profile

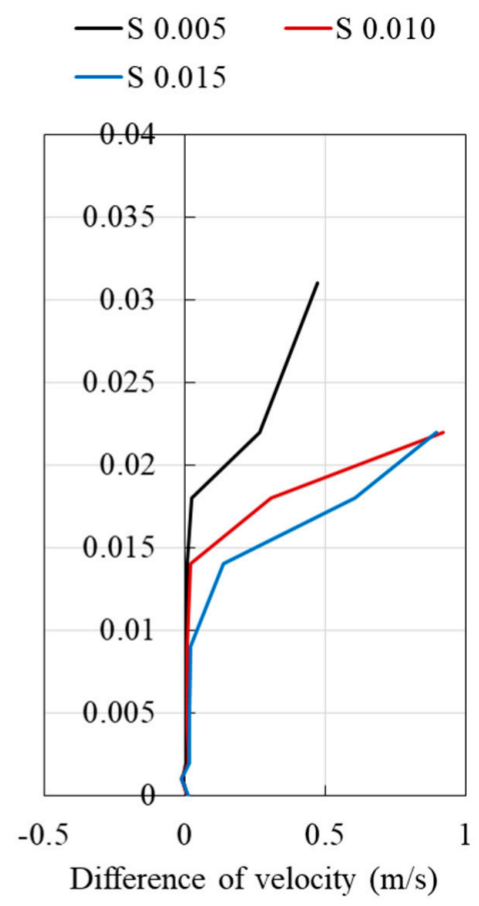

(b) Difference of velocity

Figure 7. Centerline velocity profile (a) and their differences (b) (Ci: circular pipe, Mo: complex cross-section module, the numbers beside $\mathrm{Ci}$ and $\mathrm{Mo}$ are slope, $\mathrm{S}$ : slope).

\subsection{Tractive Force}

Table 4 shows the parameters that are measured at the two waterways. At a flow rate of approximately $0.4 \mathrm{~L} / \mathrm{s}$, the two waterways have a transitional flow. Manning's equation is suitable for a very rough flow; thus, it is not perfectly appropriate for the flow of this experiment, which has a low Reynolds number [15]. The flow rate of the circular pipe was measured to be $2 \%$ higher, which is negligible. The average flow velocity, hydraulic radius, Reynolds number, and the average shear stress are all lower in the circular pipe than the complex cross-section module. Accordingly, the complex cross-section module is more advantageous than the circular pipe when the hydraulic characteristics are compared based on the changes in the cross-sectional shape.

Table 4. Experimental parameters for the circular pipe and the complex cross-section module (slope: 0.01 , pipe material: PVC), the discharge $Q(\mathrm{~L} / \mathrm{s})$, average velocity $U_{a v}(\mathrm{~m} / \mathrm{s})$, hydraulic radius $R_{h}(\mathrm{~m})$, Reynolds number $R e$, and the average shear stress $\left(\mathrm{N} / \mathrm{m}^{2}\right)$.

\begin{tabular}{cccccc}
\hline Test Case & $Q(\mathrm{~L} / \mathbf{s})$ & $U_{a v}(\mathrm{~m} / \mathbf{s})$ & $R_{h}(\mathbf{m})$ & $R e$ & $\tau=\gamma R S\left(\mathrm{~N} / \mathbf{m}^{2}\right)$ \\
\hline Circular pipe & 0.423 & 0.371 & 0.0089 & 3285 & 0.65 \\
Complex cross-section module & 0.412 & 0.436 & 0.0113 & 4902 & 0.829 \\
\hline
\end{tabular}

Table 4 demonstrates that the shear stress of the complex cross-section module is greater, which was verified through a sediment transport test. The sand was scattered on the waterways as shown in Figure 4, which is also illustrated in Figure 8. The sand flowed at a fast speed due to the free falling of the water at the upstream of the waterways, but sedimentation started to occur as the flow became stable. Small sand grains flowed down while floating, but coarse sand grains rolled on the 
bottom. Floating sand grains flowed down quickly at the flow velocity of the water surface. In contrast, the coarse sand grains traveled at a slow speed, which were easy to observe. The average flow velocity of the complex cross-section module was faster; therefore, the apparent moving speed of the sand grain was also faster.

The largest sand grains collected at the end of the waterways were selected and arranged as shown in Figure 9. According to a study by Hwang et al. [20], the particle size of the sand grains was analyzed by using digital images. The width and length of the largest particles collected from each waterway are $2.49 \mathrm{~mm}$ and $2.2 \mathrm{~mm}$ for the circular pipe as shown in Figure 9a, and $3.07 \mathrm{~mm}$ and $2.91 \mathrm{~mm}$ for the complex cross-section module as illustrated in Figure 9b. Equation (3) indicates that the flow has a greater shear stress when larger particles are transported. The size of the sand transported through the complex cross-section module is greater and so is the tractive force.

This experimental result can be verified by using the transportable maximum sand grain size $\left(D_{s}\right)$ of the Shields diagram [21]. Based on the parameters listed in Table 4 and the assumptions of kinetic viscosity $=10^{-6} \mathrm{~m}^{2} / \mathrm{s}$, specific gravity of soil $=2.65 \mathrm{~g} / \mathrm{cm}^{3}$, and critical shear stress = average shear stress, the $D_{s}$ of the circular pipe is $1.1-1.2 \mathrm{~mm}$ and the $D_{s}$ of the module is $1.4-1.5 \mathrm{~mm}$ by applying a trial-and-error method to determine the boundary Reynolds number $\left(R_{e^{*}}\right)$ and dimensionless Shields parameter $\left(F_{*}\right)$ (Table 5). The $D_{s}$ specified in Table 5 is different from that in the experiment result because of assumptions including the difference in the shape and specific gravity of each sand grains, the Shields diagram shows that the transport ability of the complex cross-section module is better than the circular pipe.

Table 5. Transportable maximum sand grain size $\left(D_{s}\right)$, boundary Reynolds number $\left(R_{e_{*}}\right)$, and dimensionless shields parameter $\left(F_{*}\right)$ in this experiment (discharge: $0.4 \mathrm{~L} / \mathrm{s}$, slope: 0.01 , pipe material: PVC).

\begin{tabular}{cccc}
\hline Test Case & $\boldsymbol{R}_{\boldsymbol{e}}{ }^{*}$ & $\boldsymbol{F}_{*}$ & $\mathbf{D}_{\mathbf{s}}$ \\
\hline Circular pipe & $28-31$ & $0.034-0.038$ & $1.1-1.2$ \\
Complex cross-section module & $40-43$ & $0.035-0.038$ & $1.4-1.5$ \\
\hline
\end{tabular}

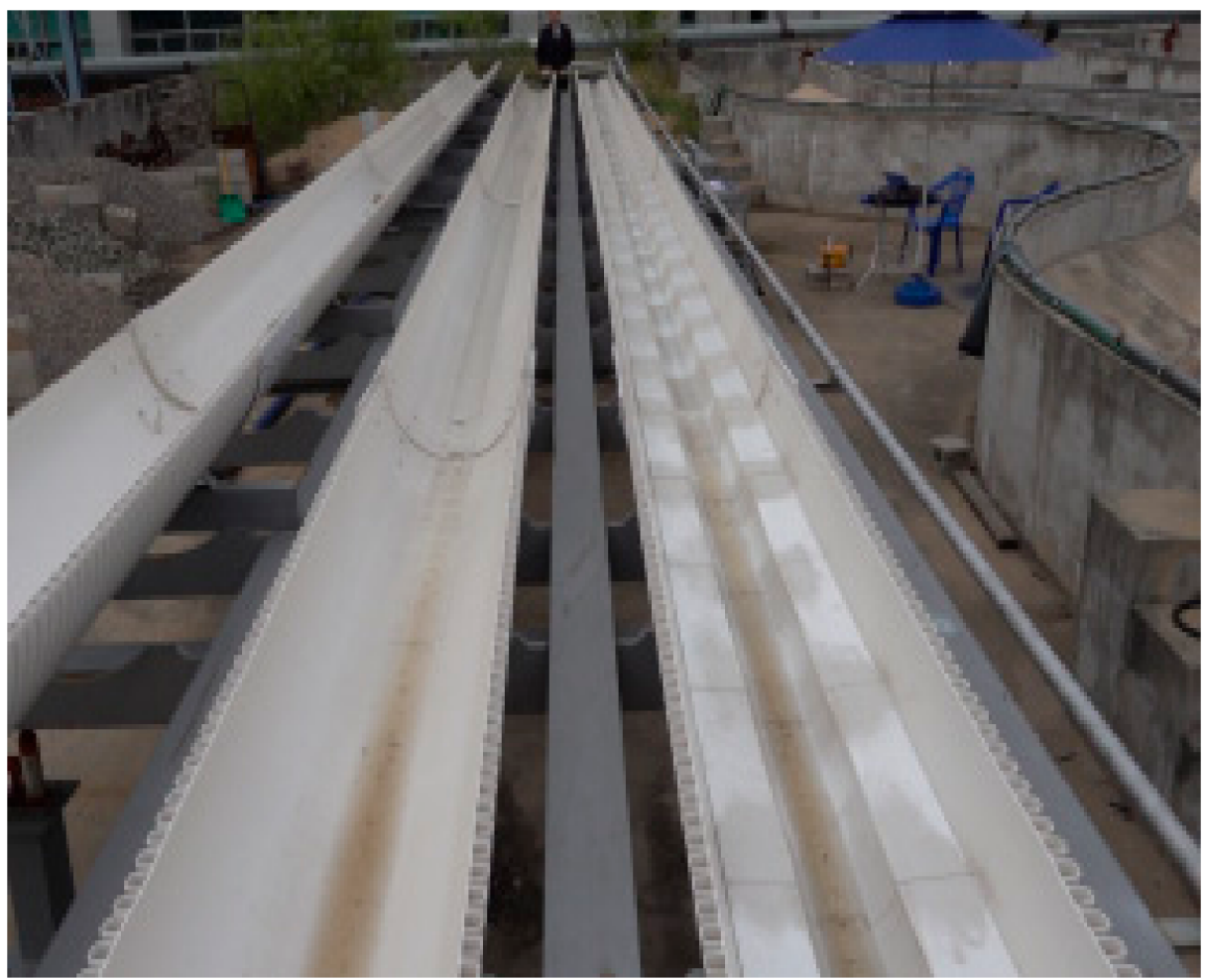

Figure 8. Transportation of the sediment on the experimental sewer pipe lines. 


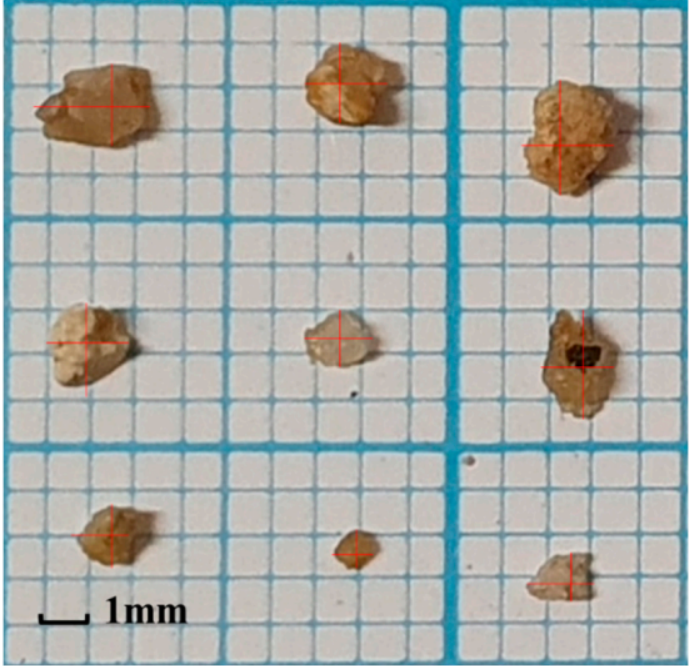

(a) From circular pipe

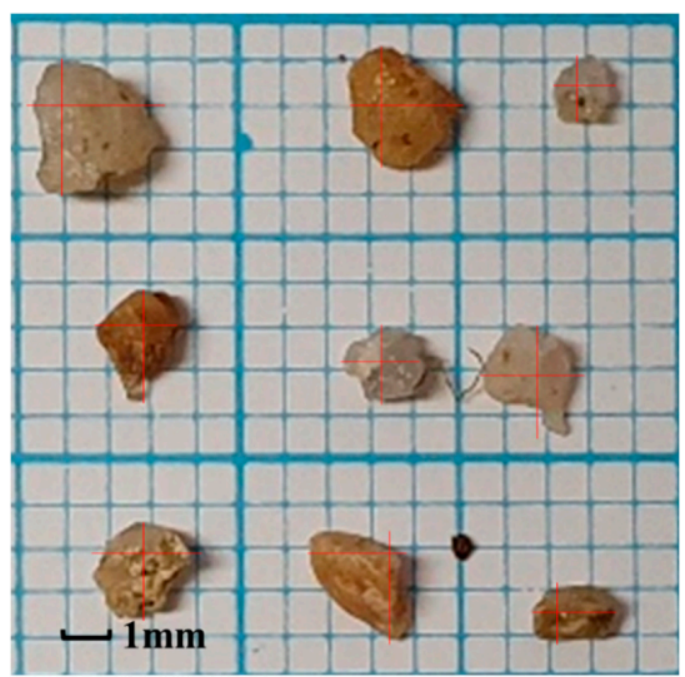

(b) From complex cross-section module

Figure 9. Largest sand grains being transported from circular pipe (a) and complex cross-section module (b).

There are various theories on the analysis of sedimentation in sewer pipes; however, no general question exists since most theories are satisfied only under a certain condition. The CIRIA (Construction Industry Research and Information Association) report evaluated the sediment mobility based on the full pipe flow [22], which is not applicable to the flow in the combined sewer system on non-rainy days. The DuBoys equation or the Meyer-Peter and Muller equations are related to bed load transport, in which the hydraulic radius or shear rate are considered to be the main parameters [23,24]. However, the hydraulic radius and shear rate are not simply proportional to the amount of transported bed load; thus, they cannot be easily evaluated as they are related to other parameters in various forms. In that respect, this experiment intuitively evaluated the tractive force of the two waterways in a controlled environment.

Sedimentation occurs in all sewer pipe systems to a certain extent, in which the roughness and cross-section alters the sediments that are influenced by the velocity field [5]. Therefore, an analysis on the sedimentation must be taken into consideration to examine the efficiency of a complex cross-section module from a long-term perspective. This aspect will be compared by constructing an actual test bed and monitoring the results.

In the full pipe flow, the discharge capacity is reduced as the cross-sectional area of the flow is decreased due to the complex cross-section module. The decrease is around $11 \%$ according to the calculation based on Manning's equation. Typically, the combined sewers are designed so that the water level is $50 \%$ or below the pipe diameter for the design rainfall; thus, an $11 \%$ decrease is negligible with respect to the entire cross-sectional area.

\section{Conclusions}

Since a high quality of life is crucial from a cultural perspective, more emphasis is being placed on the problem of sewer odor. Among the various causes of sewer odor, sedimentation in the combined sewer system on non-rainy days is one of major causes of odor. The complex cross-section module is a device for increasing the flow velocity by enlarging the hydraulic radius by using a separate waterway for sewage at the bottom of the sewer pipe. Considering how only circular or square type sewer pipes are currently installed for the economic feasibility of construction, the complex cross-section module can increase the flow velocity on non-rainy days while retaining the existing system. In this study, we observed the effect of an increased hydraulic radius on the flow velocity by keeping the roughness coefficient constant, and the average flow velocity was increased by approximately $14 \%$. However, an increase in the average flow velocity will be even greater if the difference between the 
roughness coefficient of the outdated concrete pipes is increased by deterioration and if PVC is applied. Furthermore, the complex cross-section module has a stronger tractive force on the sand movement when using an artificial waterway, which resembles an actual sewer pipe.

The applicability of the module varies with geographies. The results are site specific, the actual flow conditions (stormwater and sewage discharge) determines the dimensions to be applied. To apply this to other areas, this module should be re-designed using stormwater and sewage data of the area because the module of this study is suitable only for Korea because the efficiency of the module is the maximum when the water way size is equivalent to that of the sewage. The construction method for the module is not yet established. In the future, to further improve convenience and the economy of construction, we will optimize the construction method of applying a complex cross-section module to the test bed.

Author Contributions: Conceptualization, software, and writing—original draft preparation, H.W.J.; visualization, S.S.Y.; writing - review and editing, D.D.K.; investigation and supervision, J.-H.K. All authors have read and agreed to the published version of the manuscript.

Funding: This research is supported by the Korea Ministry of Environment (MOE: 2017-0007-00001) through the "Public Technology Program based on Environmental Policy".

Conflicts of Interest: The authors declare no conflict of interest.

\section{References}

1. Korea Construction Standards Code. Available online: http://www.kcsc.re.kr/Search/ListCodes/102057\# (accessed on 11 February 2020).

2. Starzec, M.; Dziopak, J.; Słyś, D. An analysis of stormwater management variants in urban catchments. Resources 2020, 9, 19. [CrossRef]

3. Kordana, S.; Styś, D. An analysis of important issues impacting the development of stormwater management systems in Poland. Sci. Total Environ. 2020, 727, 138711. [CrossRef] [PubMed]

4. Lee, J.H.; Park, Y.J.; Kim, I.H.; Nam, I.G.; Kim, H.S.; Lee, J.K. Engineering of Water Supply and Sewerage; Goomibook: Seoul, Korea, 2008; pp. 267-277.

5. Ashley, R.M.; Bertrand-Krajewski, J.L.; Hvitved-Jacobsen, T.; Verbanck, M. Solids in Sewers-Characteristics, Effects and Control of Sewer Solids and Associated Pollutants; IWA Publishing: London, UK, 2004; pp. 7-163.

6. San Francisco. City and County of San Francisco 2030 Sewer System Master Plan. 2009. Available online: https://sfwater.org/modules/showdocument.aspx?documentid=586 (accessed on 23 November 2020).

7. WESD and WCSD (Wastewater Engineering Services Division \& Wastewater Collection Systems Division). Collection System Odor Control Master Plan 2017. 2017. Available online: https://www.lacitysan.org/cs/ groups/sg_cw/documents/document/y250/mdiw/ \{\}edisp/cnt020340.pdf (accessed on 23 November 2020).

8. Ji, H.W.; Yoo, S.S. The measures to reduce sewer odor in South Korea through sewer odor reduction system in Los Angeles and San Francisco. J. Korean Soc. Water Wastewater 2018, 32, 445-451. [CrossRef]

9. Pochwat, K.; Kida, M.; Ziembowicz, S.; Koszelnik, P. Odours in sewerage-A description of emissions and of technical abatement measures. Environment 2019, 6, 89. [CrossRef]

10. Beichert, J. Influence of sewer sediments on the overflow load for various combined sewer systems. Water Sci. Tech. 1992, 25, 217-224. [CrossRef]

11. Ahyerre, M.; Chebbo, G. Identification of in-sewer sources of organic solids contributing to combined sewer overflows. Environ. Tech. 2002, 23, 1063-1073. [CrossRef] [PubMed]

12. Schladweiler, J.C. The History of Sanitary Sewer: Pipes-Brick; AZ Water Association; NASSCO; Collection Systems Committee of the Water Environment Federation. 2020. Available online: http://www.sewerhistory. org/photosgraphics/pipes-brick/ (accessed on 24 July 2020).

13. Bizier, P. Gravity Sanitary Sewer Design and Construction; American Society of Civil Engineers and Water Environment Federation: Reston, VA, USA, 2007.

14. Regueiro-Picallo, M.; Naves, J.; Anta, J.; Puertas, J.; Suárez, J. Experimental and numerical analysis of egg-shaped sewer pipes flow performance. Water 2016, 8, 587. [CrossRef]

15. Douglas, J.F.; Gasiorek, J.M.; Swaffield, J.A. Fluid Mechanics, 3rd ed.; Longman: Harlow, UK, 1995; pp. 460-474. 
16. George, E.P.; Hunter, J.S.; Hunter, W.G. Statistics for Experimenters: Design, Innovation, and Discovery; Wiley: New York, NY, USA, 2005; pp. 27-33.

17. ANSYS CFX. ANSYS CFX-Solver Theory Guide; ANSYS CFX Release: Canonsburg, PA, USA, 2012; pp. $69-118$.

18. Haestad, M.; Walski, T.M.; Barnard, T.E.; Harold, E.; Merritt, L.B.; Walker, N.; Whitman, B.E. Wastewater Collection System Modeling and Design; Haestad Press: Waterbury, CT, USA, 2004.

19. Chaudhry, M.H. Open-Channel Flow, 2nd ed.; Springer Science \& Business Media: New York, NY, USA, 2008; pp. 9-11.

20. Hwang, T.-J.; Cho, J.-Y.; Lee, K.-H. Gradation curve of aggregate using digital image process. J. Korean Soc. Hazard Mitig. 2010, 10, 31-37.

21. Guo, J. Empirical model for Shields diagram and its applications. J. Hydraul. Eng. 2020, 146, 04020038. [CrossRef]

22. Ackers, J.C.; Butler, D.; May, R.W.P. Design of Sewers to Control Sediment Problems; Construction Industry Research and Information Association: London, UK, 1996.

23. Julien, P.Y. Erosion and Sedimentation; Cambridge University Press: Cambridge, UK, 1998; pp. 161-166.

24. Mayerle, R.; Nalluri, C.; Novak, P. Sediment transport in rigid bed conveyances. J. Hydraul. Res. 1991, 29, 475-495. [CrossRef]

Publisher's Note: MDPI stays neutral with regard to jurisdictional claims in published maps and institutional affiliations.

(C) 2020 by the authors. Licensee MDPI, Basel, Switzerland. This article is an open access article distributed under the terms and conditions of the Creative Commons Attribution (CC BY) license (http://creativecommons.org/licenses/by/4.0/). 